\title{
Exploring the training mode of graduate students' innovative talents from the perspective of internationalization
}

\author{
Moxin Xiao, a, *, Xiaoyu Zhang1, b, Xin Yuan+1, c, Peng Li, d, Wei Wang1, e \\ ${ }^{1}$ Harbin Engineering University, College of Automation, Harbin, China \\ axmx1981@hrbue.edu.cn, bzhangxiaoyu@hrbeu.edu.cn, cyuanxin@hrbeu.edu.cn, \\ dlipeng@hrbeu.edu.cn, ewangwei10@hrbeu.edu.cn
}

${ }^{*}$ Corresponding author

Keywords: Internationalization, Innovative, Training

Abstract. From the perspective of internationalization, in view of the current situation of postgraduate training at home and abroad, the problems and problems to be solved in the process of postgraduate training in China are analyzed, and the training mode of innovative talents is put forward from the aspects of curriculum system, training mode and policy mechanism.

\section{以国际化视角探索研究生创新人才培养模式 \\ 肖模昕 ${ }^{1,}$ a * * 张晓宇 ${ }^{1, b}$, 原新 ${ }^{1,}$, 李芃 ${ }^{1,}$, 王巍 ${ }^{1,}$ \\ ${ }^{1}$ 哈尔滨工程大学自动化学院, 哈尔滨, 中国 \\ axmx1981@hrbue.edu.cn, bzhangxiaoyu@hrbeu.edu.cn, cyuanxin@hrbeu.edu.cn, dlipeng@hrbeu.edu.cn, ewangwei10@hrbeu.edu.cn}

*通讯作者

关键词：国际化；创新；人才培养

中文摘要：以国际化视角，针对国内外研究生培养现状，分析我国研究生培养过程中存在的 问题和亟待解决的问题，并从课程体系、培养模式、政策机制等方面提出创新人才培养模式。

\section{1 引言}

2015 年底, 国家正式提出《统筹推进世界一流大学和世界一流学科建设总体方案》(以 下简称 “双一流”)，作为 “十三五” 期间我国高等教育发展的明确目标和任务要求。方案特 别强调高等教育的国际化发展, 明确提出 “加强与世界一流大学和学术机构的实质性合作, 将国外优质教育资源有效融合到教学科研全过程, 开展高水平人才联合培养和科学联合攻关”。 2017 年初, 教育部、财政部、国家发改委联合印发了《统筹推进世界一流大学和一流学科建 设实施办法 (暂行) 》, 提出要建设世界一流大学和一流学科, 这是党中央和国务院做出的重 要决策。该办法强调 “双一流” 建设高校需在拔尖创新人才培养模式方面成果显著, 积极推 进课程体系和教学内容改革, 资源配置和政策导向体现人才培养的核心地位, 质量保障体系 完善, 有高质量的研究生教育 ${ }^{[1]}$ 。通过大规模的国际化培养, 塑造我国高校研究生教育的新 模式，成为支撑我国高校加快建设 “双一流” 的关键环节。研究生培养过程是在特定的教育 理念和精神指引下, 依据特定的教育规范、制度和人才培养目标, 设计相对稳定的教学课程 和科学研究体系, 结合校内外理论学习和能力实践所开展的专业人才培养的动态过程 ${ }^{22]}$ 。高 水平的研究生教育是世界一流大学和一流学科的主要特征, 培养面向国际的、具有创新精神 
和实践能力的综合素质高的复合型人才, 成为高等研究生教育生培养的重要目标。因此, 如 何进行研究生培养的进一步创新, 推进研究生培养国际化, 提高研究生培养质量, 成为我国 研究生培养亟待解决的重要问题。

\section{2 我国研究生国际化培养现状及问题分析}

随着经济全球化的发展趋势, 各国对人才需求竞争越来越激烈, 这尤其需要培养具有国 际竞争力的创新型人才。为增强中国高等教育培养的国际竞争力, 培养具有国际视野, 能够 与世界接轨的高素质创新人才, 高等学校的研究生教育肩负着培养国际化高素质拔尖人才的 重任。近几年, 我国研究生教育虽然取得一定进步, 各高校逐步开始重视研究生国际化培养, 不断增加研究生国际交流机会, 并已培养了大批具有创新精神和实践能力的优秀研究生。但 研究生培养质量尤其是研究生的国际化学术素养仍与发达国家高水平仍存在一定差距, 如研 究生国际交流能力欠缺, 国际化视野不够开阔等。在研究生出国交流方面, 硕士和博士通过 国家留学基金委等方式每年出国访学、参加会议或联合培养的人数比例较低, 不足以覆盖全 部研究生, 这也限制了研究生的开放式培养, 使得研究生国际合作不够深入, 国际交流不够 充分。因此, 进一步改革研究生培养体系, 增强国际化培养模式, 创建多种国际交流方式, 成为培养具有国际视野、适应国际化浪潮的高精尖人才, 成为目前我国研究生培养的必然趋 势。

\section{3 提高研究生国际化培养的措施}

\section{1 构建国际化研究生培养课程体系}

通过建设一批 “与国外高水平学者共建课程”、“精品双语课程” 等, 加强与国际高水平 学术机构的交流与合作, 提高研究生教学质量。

为充分借鉴国际高水平大学在研究生教学中的经验, 促进研究生课程教学内容及教学方 式的改革, 进一步完善研究生课程体系, 提高研究生教学的师资水平, 培养研究生的理论基 础与创新能力, 决定实施 “与国际高水平学者共建研究生课程” 项目。拟在进一步完善研究 生课程体系的基础上, 促进研究生课程教学内容及教学方式的改革, 提高课程建设水平; 加 强研究生教育国际化, 促进研究生导师、任课教师与国外高水平学者的合作, 提高研究生教 学师资水平。学校对于项目给予一定的经费资助。共建合作者应为国际知名大学长期工作、 学术造诣高、有丰富的本学科研究生课程教学经验、曾多次讲授过相关课程的高水平学者。 每门共建课程由 3-5 位我校教授、副教授与共建合作者共同组成共建小组。共建小组负责讨 论并确定课程内容、教学方式、教学要求、教材及参考文献、师资培养等相关事项。

工信部 “研究生教育优秀工程指标体系” 研究生教育国际化 A 级指标提出 “全校使用英 语授课或英文教材或外籍教师授课的课程比例达到 5\%以上”。研究生双语精品课程是 “具有 一流教师队伍、一流教学内容、一流教学方法、一流教材、一流教学管理” 等特点的示范性 课程。建设的目的是通过为研究生提供优质的教学资源来培养具有创新能力和国际竞争力的 高素质创新人才。课程应反映学科前沿的科技成果, 采用现代化教学方式, 教学过程中贯穿 创新方法和科学思维, 并重视创新型实验和实践, 以研究生精品课程建设带动其他课程建设, 通过研究生双语精品课程建设提高学科整体教学水平, 并保证研究生精品课程的可持续发展。

全国工程专业学位研究生教育指导委员会 2014 年主任委员（扩大）会议研究决定，应积 极抓住 2012 年以来, “大规模在线开放课程” (Massive Open Online Courses, MOOCs) 在全 球迅速兴起, 给传统高等教育教学带来巨大影响这一重大机遇, 尽快启动工程专业学位研究 生教育在线教学工作, 促进教育理念和教学方式方法的转变, 切实推动优质教学资源在各培 养单位中的共享, 着力提高工程专业学位研究生教育教学质量。因此, 高校将在教师鼓励、 课程制作、在线教学、推介推广等方面给予支持, 积极建设一批在线开放课程, 以促进教学 
资源共享，以及扩大国际学术交流。

\section{2 打造国际化研究生培养模式}

国际化教育是目前世界研究生教育的主要目标，也是世界一流大学的建设目标。打造国 际化的研究生培养模式, 需要鼓励教师科研与教学相结合, 将科研成果融入课堂教学, 不断 吸取国际最新前沿科学研究进展信息, 定期开展学术交流与研讨, 扩增学生国际视野, 提高 研究生国际学术水平。

通过定期邀请国内外高水平专家来校进行短期讲学、聘请国外知名教授作为学校客座教 授, 积极开展与国外高水平大学或科研机构的科研合作, 全面打造国际化研究生培养模式。 通过广泛的招收各国留学生, 努力创造激励政策, 吸引优质国际生源来营造学校国际化氛围, 为国内研究生提供充分的国际交流空间和条件。

在教学方式上，通过多种教学方法，如研讨式、报告式、讲座式、交流等方式，逐步提 升研究生自主学习和探究式的学习兴趣, 与国际发达国家教学方式接轨。通过阅读文献报告, 学术前沿讲座等教学方式, 让学生掌握学科发展前沿信息, 以及未来发展方向动态, 与国际 科研紧密联系。

\section{3 建立国际化研究生培养资助体系}

学校应制定一系列相应的政策，如创新型人才国际合作联合培养项目、国际会议资助体 系、青年教师出国访学等, 鼓励教师和学生到国内外高水平大学或研究机构进行访学或参加 学术会议, 以加强国际交流水平, 进一步提升研究生的创新能力。

创新型人才国际合作联合培养项目是为配合国家战略、教育领域综合改革，培养更多创 新型、紧缺型、复合型国际化人才, 选派优秀博士、硕士研究生进行联合培养。为派出人员 提供一定的资助, 并根据合作计划, 双方导师为学生制定工作学习计划, 安排学生在国外学 习期间应解决的实际内容, 在合作机构参加科研工作, 参与实验项目按要求完成相关工作, 充分利用外方先进的实验设施和相关资源, 进行科学研究和理论学习。

为服务国家经济社会发展和人才强国战略，培养一批国家急需的具有国际视野、通晓国 际规则, 能够参与国际事务和竞争的高层次应用型专门人才, 设立并实施国家公派硕士研究 生项目。鼓励依托导师或学院已有科研合作渠道开展对外联系; 申请者可利用国家留学基金 委现有与国外大学、科研机构合作项目开展对外申请。

为支持师生进行学术交流, 紧跟国际学术前沿, 提高学术研究水平, 根据国家及学校相 关规定, 制定了国际学术会议资助办法。通过资助高层次创新人才高水平国际学术会议, 提 高师生的国际交流能力和水平。

\section{4 结束语}

提高研究生的国际化水平，培养具有国际视野的高素质研究生，是适应国家 “双一流” 建设总体目标的一项重要工作之一。通过改革课程体系, 提高国际化师资力量, 加强国际学 术交流等一系列措施, 可以进一步提高研究生的国际化培养质量和创新能力, 从而培养出一 批适应国家社会发展的、能够进行有效国际交流的创新型研究生。

\section{致谢}

本文为哈尔滨工程大学教育教学改革研究项目《国际化视野下研究生创新人才培养探索 与实践》、《校-院 (所) 合作协同创新特色研究生培养机制研究--以控制工程专业型硕士为例》, 黑龙江省教育科学规划专项课题《新经济形势下的黑龙江高校工科博士人才培养机制研究》 的阶段性成果之一。 


\section{References}

[1]. Yishu Luo, The " double first class " under the background of the construction of educational system through master-doctor graduate education reform through, Textile and Apparel Education, Vol. 32 , No.5, 2017;

[2]. Ronghua Zhang, Direction and strategy: Key issues of postgraduate training in Universities under the background of "double first class", Shaanxi Normal University holds humanities and social sciences postgraduate training quality to enhance high-end forum, Chinese Social Science newspaper , vol.004, 2018; 